\title{
Development and Validation of Fear of Relapse Scale for Relapsing- Remitting Multiple Sclerosis
}

Ali Khatibi ${ }^{1 *}$, Nahid Moradi ${ }^{2}$, Naghmeh Rahbari ${ }^{3}$, Taranom Salehi ${ }^{4}$, Mohsen Dehghani ${ }^{5}$

1 Department of Neurology and Neurosurgery, McGill University, Montreal, Canada

2 Department of Neurology, Royal Melbourne Hospital, Australia

3 Institute for Cognitive Science Studies, Tehran, Iran

4 Department of Psychology, Allameh University, Tehran, Iran

5 Department of Psychology, Shahid Beheshti University, Tehran, Iran

${ }^{*}$ Corresponding Author

Ali Khatibi, PhD

Department of Neurology and Neurosurgery,

McGill University,

Montreal, QC

Canada

Email: ali.khatibi@gmail.com

Tel: +1-514-398-5564 


\section{Abstract}

Background: Multiple Sclerosis (MS) is a potentially debilitating chronic disease in most cases diagnosed after an acute relapse and characterized by the occurrence of relapse in most patients. Due to the unknown course of the disease patients in early phases must deal with the stress of anticipation of a relapse and unpredictable consequences of that relapse. Objective: This is the first effort to develop a self-report measure of Fear of Relapse (FoR) in patients with Relapsing-Remitting (RR) MS. Methods: A 31- item scale was created from in-depth clinical interviews with 33 RRMS patients. This scale was completed by 168 RRMS patients (51 patients completed the scale one more time a month later) who completed the Intolerance of Uncertainty Scale (IUS) and Depression, Anxiety and Stress Scale (DASS) as well. Results: A factor analysis revealed three components, and five items failed to load on any of them. The final version of the scale consisted of 26 items. Two-components solution factor analysis after pooling the FoR items once with DASS items and once with IUS items revealed independency of the FoR from previously developed scales. Cronbach's Alpha was equal to 0.92. Test-retest reliability for total score was equal to $0.74(p<0.001)$. Conclusion: The FoR scale proved to be a highly reliable and valid measure in RRMS patients and application of that in future studies trying to create a psychological profile of patients at earlier stages of the disease can help researchers and clinicians to have a more comprehensive image.

Keywords: Relapsing-Remitting Multiple Sclerosis; Fear of Relapse; Anxiety; Validation; Scale Development; Psychometry 


\section{Introduction}

Multiple sclerosis is a chronic and potentially debilitating disease of the nervous system that affects many people of all ages. Early symptoms vary and may depend on one's age, life history, and other factors. Diagnosis normally follows the first major occurrence of sub-acute neurological symptoms which include but are not limited to vision problems, sensory-motor deficits, fatigue, balance problems, and dizziness. The progress of the disease also depends on many factors based on which people can be divided into four subgroups in regard to the clinical course of the disease, Relapsing-Remitting MS (RRMS), Secondary-Progressive MS (SPMS), Primary-Progressive MS (PPMS), Progressive-Relapsing MS (PRMS). The course of the disease is unpredictable but in around $90 \%$ of the patients ( $85 \%$ RRMS and $5 \%$ PRMS), it is specified with the occurrence of relapses which manifest similarly to the first attack, with the same, less or more severity. A new relapse is usually associated with the formation of new inflammatory lesions somewhere in the Central Nervous System (CNS) which accompanies acute new demyelination or re-activation of an old lesion. These relapses have short and longterm consequences and might lead to the accumulation of disability.

Many previous studies have shown that anxiety is an undetachable part of life in patients with chronic diseases (Wells, Golding et al. 1988). Anxiety is built on the ruins of fear and the source of fear depends on the underlying condition. For example, in chronic pain, fear of pain is due to the patient's expectations about the influence of pain on his/her personal and social life and how long-term pain causes disability in both (Crombez, Vlaeyen et al. 1999). Fear of progression has been found to be the pillar of the anxiety problems of patients suffering from chronic diseases like cancer and diabetes mellitus (Duran, Herschbach et al. 1995, Herschbach, Duran et al. 1997, Herschbach, Berg et al. 2005). A previous effort to develop a tool for measuring fear of progression in chronically ill patients resulted in FoP-Q which has been shown to have proper psychometric properties (Herschbach, Berg et al. 2005).

A source of anxiety in the earlier stages of multiple sclerosis is the relapse itself. Patients diagnosed with MS don't know when they might have their next relapse and don't have any estimation about the severity of the relapse and its consequences. Generally, it is well-accepted that a new relapse is a sign of progression of the disease and has its own complications. It has also been suggested that fear of progression (in its general term and as an emotional response) is related to the depression observed in patients with MS while it is not correlated with gender, age, disease duration, and the stage of the disease (Nielsen, Saliger et al. 2018). 
Presentations and post-diagnosis course differ among patients with MS. Part of this diversity are related to the stage or the type of the disease, but it does not explain the whole image. It is important to realize that each stage of MS is characterized by specific complications and stressors albeit the fact that demyelination in the CNS might be present throughout its course (Burns, Nawacki et al. 2014). Any tool that wants to give a clear image of the patients in a specific stage must take this into account. Existing self-report measures targeting psychological impacts of MS on patients are limited in this regard. It has been suggested that psychological and pharmaceutical interventions both are necessary to improve the quality of life in patients (Strober 2018). It matters to have measures that can assess the fear related to the disease and the relapses. These measures then enable evaluating the efficiency of the proposed interventions. We firstly aimed to develop a new tool concentrated on measuring the fear of relapse among patients with RRMS. Secondly, we aimed to investigate the psychometric properties of this measure in an independent sample of patients and to compare patients at different stages.

\section{Method}

\subsection{Interviews and item extraction}

A semi-structured in-depth interview was conducted with 33 (18 females) patients with RRMS. Patients were recruited from Sina specialized MS research and treatment center, Tehran, Iran. For all patients, Persian was their native language and they had received their diagnosis in the previous 5 years. They were all receiving disease-modifying treatments for their condition. Expanded Disability Status Scale score for all these patients was below 4. The study was approved by the ethics committee of the department of psychology at Shahid Beheshti University and all subjects gave written consent prior to their participation.

The interview was based on pre-selected questions in four main domains: (i) demographics and daily life experiences and difficulties (ii) cognitive problems (iii) psychological problems (iv) social challenges. The interviews took 60 minutes at most. The sessions were audio-recorded and transcripted afterward and ATLAS.TI-6 was used for the organization of the interview material.

A number of keywords that the literature suggested them to be involved in individuals' fear of relapse in MS were selected. This included: physical difficulties, stress, anxiety, relapse, 
hospitalization, disease progress, fear, worries, and health problems. A total number of 156 statements were found to contain one or more of these keywords. The content of all 156 items was reviewed by three independent experts and those with similar statements, unclear complaints, and non-relevant content was removed and summarized. The final list contained 31 items judged by their clarity, difficulty in understanding and relevance. Each item described the patient's thoughts about symptoms that could be associated with relapse or its consequences. $A$ patient would be asked to choose to what degree they think these statements are true about them. A 5-point Likert scale was chosen for responses $(0=$ Never, 1=rarely, 2=sometimes, 3= often, 4= always). A translated version of the questionnaire is provided as supplementary material (translated from Persian to English, back-translated by an independent experienced translator and based on the back translation the English translation was adapted).

\subsection{Psychometric evaluation}

\subsubsection{Participants}

A total number of 168 patients with RRMS (142 females; age 17-57; mean=32.65 \pm 8.2 ) were recruited from multiple centres in Tehran, Iran. These patients received either a paper version of the questionnaire or a link to the online version. The study was approved by the ethics committee of the Department of Psychology at Shahid Beheshti University and participants had given informed consent prior to participation.

\subsubsection{Other self-report measures}

\subsubsection{Depression Anxiety Stress Scale (DASS-21; (Lovibond and Lovibond 1995))}

DASS-21 is a self-report measure of depression, anxiety and stress among clinical and nonclinical populations and is reported to have good to excellent psychometric properties in different settings and populations (Norton 2007). Each item comprises a statement about feelings and experiences that the reader had to select to what degree it applied to them in the past week on a 4-point Likert scale ( $0=$ Did not apply to me at all; $3=$ Applied to me very much, or most of the time). This measure and the 42-item variant has been translated to Persian and is widely used in different studies and has shown good to excellent psychometric properties (Cronbach's alpha>0.8; (Akbari, Dehghani et al. 2016, Dehghani, Mohammadi et al. 2018)).

\subsubsection{Intolerance of Uncertainty (IUS-27; (Freeston, Rhéaume et al. 1994))}

IUS-27 is a self-report measure, with 17 items describing people's reaction to uncertainties in life. Subjects have to rate each item on a 5-point Likert scale (1=Not at all characteristic of me; 
$5=$ Entirely characteristic of me). This measure is suggested to capture the fear of the unknown and anxiety related to that and is proved to have good psychometric properties (Buhr and Dugas 2002). The Persian version of this scale is widely used in different settings and is showed to have good psychometric properties (Khaje Mansoori, Mohammadkhani et al. 2016).

\subsubsection{Procedure}

After receiving information about the nature of the research and the aim of the current study participants received either the paper copy of the study or a link to complete the questionnaire online. Fifty-one patients agreed to complete the questionnaire one month later to test the reliability of the measure. The Intolerance of Uncertainty measure, which has been suggested to capture the fear of unknown happening has been selected to test the validity of the fear of relapse measure. For all analysis, the statistical significance level was set to $p<0.05$.

\section{Results}

\subsection{Properties of the Fear of Relapse Scale}

Responses to 31 items of the Fear of Relapse scale are summarized in Table 1. Total FoR score were between 0 and 113 (Mean $=41.6, S D=21.1$ ).

Table 1. Number of Responses for All Items of the Fear of Relapse Scale (Percentage)

\begin{tabular}{|l|l|l|l|l|l|l|}
\hline & Never & Rarely & Sometimes & Often & Always & Missing \\
\hline FoR_1 & $73(43.5)$ & $42(25)$ & $28(16.7)$ & $15(8.9)$ & $9(5.4)$ & 1 \\
\hline FoR_2 & $61(36.3)$ & $28(16.7)$ & $41(24.4)$ & $17(10.1)$ & $19(11.3)$ & 2 \\
\hline FoR_3 & $68(40.5)$ & $38(22.6)$ & $33(19.6)$ & $16(9.5)$ & $10(6)$ & 3 \\
\hline FoR_4 & $34(20.2)$ & $40(23.8)$ & $52(31)$ & $25(14.9)$ & $13(7.7)$ & 4 \\
\hline FoR_5 & $67(39.9)$ & $41(24.4)$ & $28(16.7)$ & $19(11.3)$ & $12(7.1)$ & 1 \\
\hline FoR_6 & $111(66.1)$ & $11(6.5)$ & $14(8.3)$ & $9(5.4)$ & $21(12.5)$ & 2 \\
\hline
\end{tabular}




\begin{tabular}{|l|l|l|l|l|l|l|}
\hline FoR_7 & $57(33.9)$ & $23(13.7)$ & $35(20.8)$ & $26(15.5)$ & $25(14.9)$ & 2 \\
\hline FoR_8 & $50(29.8)$ & $34(20.2)$ & $32(19)$ & $17(10.1)$ & $32(19)$ & 3 \\
\hline FoR_9 & $52(31)$ & $37(22)$ & $38(22.6)$ & $24(14.3)$ & $17(10.1)$ & 0 \\
\hline FoR_10 & $48(28.6)$ & $33(19.6)$ & $29(17.3)$ & $29(17.3)$ & $28(16.7)$ & 1 \\
\hline FoR_11 & $42(25)$ & $35(20.8)$ & $40(23.8)$ & $27(16.1)$ & $23(13.7)$ & 1 \\
\hline FoR_12 & $60(35.7)$ & $49(29.2)$ & $33(19.6)$ & $16(9.5)$ & $8(4.8)$ & 2 \\
\hline FoR_13 & $115(68.5)$ & $24(14.3)$ & $20(11.9)$ & $6(3.6)$ & $3(1.8)$ & 0 \\
\hline FoR_14 & $47(28)$ & $51(30.4)$ & $40(23.8)$ & $17(10.1)$ & $13(7.7)$ & 0 \\
\hline FoR_15 & $26(15.5)$ & $39(23.2)$ & $39(23.2)$ & $38(22.6)$ & $26(15.5)$ & 0 \\
\hline FoR_16 & $47(28)$ & $31(18.5)$ & $44(26.2)$ & $30(17.9)$ & $14(8.3)$ & 2 \\
\hline FoR_17 & $32(19)$ & $36(21.4)$ & $39(23.2)$ & $36(21.4)$ & $24(14.3)$ & 1 \\
\hline FoR_18 & $43(25.6)$ & $47(28)$ & $29(17.3)$ & $21(12.5)$ & $25(14.9)$ & 3 \\
\hline FoR_19 & $20(11.9)$ & $33(19.6)$ & $54(32.1)$ & $39(23.2)$ & $20(11.9)$ & 2 \\
\hline FoR_20 & $143(85.1)$ & $13(7.7)$ & $6(3.6)$ & $3(1.8)$ & $3(1.8)$ & 0 \\
\hline FoR_21 & $25(14.9)$ & $27(16.1)$ & $46(27.4)$ & $38(22.6)$ & $31(18.5)$ & 1 \\
\hline FoR_22 & $78(46.4)$ & $27(16.1)$ & $33(19.6)$ & $18(10.7)$ & $8(4.8)$ & 4 \\
\hline & $118(70.2)$ & $13(7.7)$ & $18(10.7)$ & $11(6.5)$ & $6(3.6)$ & 2 \\
\hline
\end{tabular}




\begin{tabular}{|l|l|l|l|l|l|l|}
\hline FoR_24 & $83(49.4)$ & $28(16.7)$ & $28(16.7)$ & $13(7.7)$ & $15(8.9)$ & 1 \\
\hline FoR_25 & $97(57.7)$ & $20(11.9)$ & $23(13.7)$ & $18(10.7)$ & $8(4.8)$ & 2 \\
\hline FoR_26 & $64(38.1)$ & $51(30.4)$ & $30(17.9)$ & $11(6.5)$ & $9(5.4)$ & 3 \\
\hline FoR_27 & $69(41.1)$ & $41(24.4)$ & $27(16.1)$ & $19(11.3)$ & $12(7.1)$ & 0 \\
\hline FoR_28 & $67(39.9)$ & $27(16.1)$ & $22(13.1)$ & $19(11.3)$ & $32(19)$ & 1 \\
\hline FoR_29 & $83(49.4)$ & $24(14.3)$ & $18(10.7)$ & $17(10.1)$ & $24(14.3)$ & 2 \\
\hline FoR_30 & $129(76.8)$ & $21(12.5)$ & $10(6)$ & $6(3.6)$ & $2(1.2)$ & 0 \\
\hline FoR_31 & $16(9.5)$ & $26(15.5)$ & $45(26.8)$ & $41(24.4)$ & $40(23.8)$ & 0 \\
\hline
\end{tabular}

\subsection{Internal Consistency}

Each item was correlated with the total score with a correlation value greater than 0.366 (ps $<0.001$ ), (Table 2). Cronbach's Alpha was equal to 0.924 .

\begin{tabular}{|l|l|l|}
\hline \multicolumn{3}{|l|}{$\begin{array}{l}\text { Table 2. } \\
\text { Fear of Relapse Scale }\end{array}$} \\
\hline Item & $\begin{array}{l}\text { Item-total } \\
\text { correlation }\end{array}$ & $\begin{array}{l}\text { Score (mean } \\
\pm \text { SD) }\end{array}$ \\
\hline FoR_1 & $.366^{* *}$ & $1.07(1.2)$ \\
\hline FoR_2 & $.541^{* *}$ & $1.43(1.4)$ \\
\hline FoR_3 & $.521^{* *}$ & $1.16(1.2)$ \\
\hline FoR_4 & $.594^{* *}$ & $1.65(1.2)$ \\
\hline FoR_5 & $.370^{* *}$ & $1.21(1.3)$ \\
\hline
\end{tabular}




\begin{tabular}{|l|l|l|}
\hline FoR_6 & $.453^{* *}$ & $0.9(1.5)$ \\
\hline FoR_7 & $.564^{* *}$ & $1.63(1.5)$ \\
\hline FoR_8 & $.601^{* *}$ & $1.68(1.5)$ \\
\hline FoR_9 & $.622^{* *}$ & $1.51(1.3)$ \\
\hline FoR_10 & $.575^{* *}$ & $1.74(1.5)$ \\
\hline FoR_11 & $.686^{* *}$ & $1.72(1.4)$ \\
\hline FoR_12 & $.583^{* *}$ & $1.17(1.2)$ \\
\hline FoR_13 & $.428^{* *}$ & $0.56(1)$ \\
\hline FoR_14 & $.513^{* *}$ & $1.39(1.2)$ \\
\hline FoR_15 & $.371^{* *}$ & $1.99(1.3)$ \\
\hline FoR_16 & $.548^{* *}$ & $1.6(1.3)$ \\
\hline FoR_17 & $.664^{* *}$ & $1.9(1.3)$ \\
\hline FoR_18 & $.742^{* *}$ & $1.62(1.4)$ \\
\hline FoR_19 & $.635^{* *}$ & $2.04(1.2)$ \\
\hline FoR_20 & $.305^{* *}$ & $0.27(0.8)$ \\
\hline FoR_21 & $.623^{* *}$ & $2.14(1.3)$ \\
\hline & $.453^{* *}$ & $1.09(1.2)$ \\
\hline
\end{tabular}




\begin{tabular}{|l|l|l|}
\hline FoR_23 & $.499^{* *}$ & $0.64(1.1)$ \\
\hline FoR_24 & $.497^{* *}$ & $1.1(1.3)$ \\
\hline FoR_25 & $.559^{* *}$ & $0.92(1.3)$ \\
\hline FoR_26 & $.475^{\star *}$ & $1.09(1.2)$ \\
\hline FoR_27 & $.609^{* *}$ & $1.19(1.3)$ \\
\hline FoR_28 & $.622^{\star *}$ & $1.53(1.6)$ \\
\hline FoR_29 & $.650^{* *}$ & $1.25(1.5)$ \\
\hline FoR_30 & $.298^{* *}$ & $0.4(0.8)$ \\
\hline FoR_31 & $.460^{\star *}$ & $2.38(1.3)$ \\
\hline
\end{tabular}

\subsection{Test-Retest Reliability}

Spearman's rank coefficient was selected to measure test-retest reliability for items independently. All items showed high correlation (Spearman's rank coefficients ranged from 0.349 to 0.815 ( $\mathrm{ps}<0.05)$ ). A pearson correlation conducted to measure the test-retest reliability of the total score showed to be significant $0.74(p<0.001)$. Table 3 presents results of test-retest correlation analysis.

Table 3. Test-retest reliability of the Fear of Relapse Scale

\begin{tabular}{|l|l|l|l|}
\hline $\begin{array}{l}\text { Item } \\
\text { Number }\end{array}$ & $\begin{array}{l}\text { Mean_test } \\
\text { (SD_test) }\end{array}$ & $\begin{array}{l}\text { Mean_reTest } \\
\text { (SD_reTest) }\end{array}$ & $\begin{array}{l}\text { Spearman's } \\
\text { rank coefficient }\end{array}$ \\
\hline FoR_1 & $1.07(1.2)$ & $1.84(1.1)$ & $.702^{* *}$ \\
\hline FoR_2 & $1.43(1.4)$ & $2.17(1.1)$ & $.553^{* *}$ \\
\hline
\end{tabular}




\begin{tabular}{|l|l|l|l|}
\hline FoR_3 & $1.16(1.2)$ & $2.16(1.3)$ & $.435^{* *}$ \\
\hline FoR_4 & $1.65(1.2)$ & $2.61(1.3)$ & $.539^{* *}$ \\
\hline FoR_5 & $1.21(1.3)$ & $1.93(1)$ & $.815^{\star *}$ \\
\hline FoR_6 & $0.9(1.5)$ & $1.61(1.1)$ & $.553^{* *}$ \\
\hline FoR_7 & $1.63(1.5)$ & $1.89(0.9)$ & $.661^{* *}$ \\
\hline FoR_8 & $1.68(1.5)$ & $2.39(1.4)$ & $.469^{* *}$ \\
\hline FoR_9 & $1.51(1.3)$ & $2.04(1.2)$ & $.561^{* *}$ \\
\hline FoR_10 & $1.74(1.5)$ & $2.24(1.3)$ & $.567^{* *}$ \\
\hline FoR_11 & $1.72(1.4)$ & $2.28(1.3)$ & $.478^{* *}$ \\
\hline FoR_12 & $1.17(1.2)$ & $2.04(1.1)$ & $.598^{* *}$ \\
\hline FoR_13 & $0.56(1)$ & $1.47(0.9)$ & $.620^{* *}$ \\
\hline FoR_14 & $1.39(1.2)$ & $2.22(1.1)$ & $.658^{* *}$ \\
\hline FoR_15 & $1.99(1.3)$ & $2.76(1.3)$ & $.622^{* *}$ \\
\hline FoR_16 & $1.6(1.3)$ & $2.39(1.3)$ & $.683^{* *}$ \\
\hline FoR_17 & $1.9(1.3)$ & $2.48(1.3)$ & $.735^{* *}$ \\
\hline FoR_18 & $1.62(1.4)$ & $2.17(1.4)$ & $.605^{* *}$ \\
\hline
\end{tabular}




\begin{tabular}{|l|l|l|l|}
\hline FoR_20 & $0.27(0.8)$ & $1.07(0.2)$ & $.635^{* *}$ \\
\hline FoR_21 & $2.14(1.3)$ & $2.61(1.3)$ & $.688^{* *}$ \\
\hline FoR_22 & $1.09(1.2)$ & $1.83(1)$ & $.560^{* *}$ \\
\hline FoR_23 & $0.64(1.1)$ & $1.22(0.6)$ & $.482^{* *}$ \\
\hline FoR_24 & $1.1(1.3)$ & $1.7(1.1)$ & $.377^{* *}$ \\
\hline FoR_25 & $0.92(1.3)$ & $1.67(1)$ & $.395^{* *}$ \\
\hline FoR_26 & $1.09(1.2)$ & $1.8(0.9)$ & $.664^{* *}$ \\
\hline FoR_27 & $1.19(1.3)$ & $1.83(1.2)$ & $.430^{* *}$ \\
\hline FoR_28 & $1.53(1.6)$ & $1.98(1.3)$ & $.557^{* *}$ \\
\hline FoR_29 & $1.25(1.5)$ & $1.72(1.2)$ & $.647^{* *}$ \\
\hline FoR_30 & $0.4(0.8)$ & $1.33(0.8)$ & $.349^{*}$ \\
\hline FoR_31 & $2.38(1.3)$ & $3(1.3)$ & $.432^{* *}$ \\
\hline
\end{tabular}

\subsection{Factor analysis}

A Principal axis factor with a Varimax rotation of item from the Fear of Relapse Scale was conducted on the data gathered from patients with RRMS. An examination of the Kaiser-Meyer Olkin measure of sampling adequacy suggested that the sample was factorable ( $\mathrm{KMO}=0.851$; $p<0.001)$.

The results of an orthogonal rotation of the solution are shown in Table 2. When rotated factors items with loadings less than 0.45 were excluded, the analysis yielded a three-factor solution (five items have been suggested to be removed: 1, 24, 26, 30, 31). Only one item (item number 
27) was loaded on two components. Table 4 presents the result of factor analysis. Cronbach's Alpha after removal of the above-mentioned 5 items went down from 0.924 to 0.917 .

\begin{tabular}{|c|c|c|c|}
\hline & \multicolumn{3}{|c|}{ Components } \\
\hline & 1 & 2 & 3 \\
\hline FoR_2 & 0.75 & & \\
\hline FoR_9 & 0.719 & & \\
\hline FoR_10 & 0.712 & & \\
\hline FoR_11 & 0.694 & & \\
\hline FoR_7 & 0.663 & & \\
\hline FoR_18 & 0.651 & & \\
\hline FoR_4 & 0.615 & & \\
\hline FoR_12 & 0.564 & & \\
\hline FoR_28 & 0.547 & & \\
\hline FoR_8 & 0.543 & & \\
\hline FoR_29 & 0.542 & & \\
\hline FoR_27 & 0.495 & 0.495 & \\
\hline FoR_3 & 0.488 & & \\
\hline
\end{tabular}




\begin{tabular}{|l|l|l|l|}
\hline FoR_16 & & 0.713 & \\
\hline FoR_14 & & 0.659 & \\
\hline FoR_15 & & 0.64 & \\
\hline FoR_21 & & 0.629 & \\
\hline FoR_17 & & 0.562 & \\
\hline FoR_19 & & 0.544 & \\
\hline FoR_22 & & 0.496 & \\
\hline FoR_13 & & 0.486 & \\
\hline FoR_23 & & & 0.714 \\
\hline FoR_5 & & & 0.708 \\
\hline FoR_6 & & & 0.61 \\
\hline FoR_20 & & & 0.597 \\
\hline FoR_25 & & & 0.531 \\
\hline From the table and the final version of the scale. \\
\hline
\end{tabular}

\subsection{Validity}

To test conduct validity of the Fear of Relapse scale we used a Pearson correlation analysis to examine the correlation between the Fear of Relapse Scale (total score after removing five items, three components as the result of factor analysis) and IUS score on two factors and DASS subscales (Depression, Anxiety, Stress). Table 5 presents the result of the correlation analysis. All the correlations were significant ( $p s<0.001)$. 


\begin{tabular}{|c|c|c|c|c|c|}
\hline & DASS_D & DASS_A & DASS_S & IUS_F1 & IUS_F2 \\
\hline FoR_total & $.600^{* *}$ & $.587^{\star *}$ & $.588^{* *}$ & $.513^{* *}$ & $.527^{\star *}$ \\
\hline FoR_Comp1 & $.540^{* *}$ & $.497^{* *}$ & $.542^{* *}$ & $.491^{\star *}$ & $.495^{* *}$ \\
\hline FoR_Comp2 & $.521^{* *}$ & $.546^{* \star}$ & $.520^{* *}$ & $.449^{* *}$ & $.458^{* *}$ \\
\hline FoR_Comp3 & $.400^{* *}$ & $.422^{* *}$ & $.338^{* *}$ & $.316^{* *}$ & $.358^{* *}$ \\
\hline \multicolumn{6}{|c|}{$\begin{array}{l}\text { DASS_D: Depression subscale of DASS, DASS_A: Anxiety subscale of DASS, DASS_A: } \\
\text { Stress subscale of DASS, IUS_F1: Factor } 1 \text { of the Intolerance of Uncertainty Scale, } \\
\text { IUS_F2: Factor } 2 \text { of the Intolerance of Uncertainty Scale }\end{array}$} \\
\hline
\end{tabular}

A two-component solution factor analysis pooling factor analysis-survived items of the FoR and DASS (Principal components, varimax rotation, maximum iterations for convergence $=50$, excluding values below 0.35 ) resulted in a clear separation of two scales on two components. For the DASS only items 4,15 and 19 weighted below 0.35 and for the FoR only item 20 weighted below 0.35 . For the DASS items 3,5 and 15 loaded on both components while the weight on the first component related to other DASS items (respectively 0.615, 0.592, 0.707) was much higher than the weight for on the second component related to FoR items (respectively $0.358,0.376,0.353$ ). For the FoR, only item number 16 loaded on both components while the weight for the second component related to FoR items $(0.418)$ was higher than the weight on the first component $(0.415)$.

A similar analysis using the IUS items instead for the DASS resulted in a clear separation of two scales on two components. For this analysis, only item 20 of the FoR weighted below 0.35 and was removed. In addition, only two IUS items ( 1 and 7 ) were loaded on both components. Both items were loaded on the first component (along with other IUS items; respectively 0.438 , 
0.608) higher than the second component related (along with FoR items; respectively 0.397, $0.393)$.

\section{Discussion}

The most common form of MS known as relapsing-remitting MS appears in the form of unpredictable relapses which are associated with the progress of the disease and may result in irreversible damages to the sensations and functions of a person. Like other chronic diseases, fear is an undetachable part of the disease in MS as well. The nature of fear and the source of fear have not been well-investigated in the literature of research on MS. Only a few studies investigated the fear of falling in different age groups of MS patients (Peterson, Cho et al. 2007). Understanding and management of fear in chronic disease have been suggested to be associated with the improvement in self-management in patients (Holman and Lorig 2004). Consequently, the improvement in self-management in chronic disease has been suggested to be associated with an improvement in health status, increase in self-efficacy and a reduction in hospitalization (Lorig, Sobel et al. 1999). Thus, the improvement in self-management of a chronic disease reduces the economical and emotional burden of the disease and might results in substantial increase in the quality of life of patients with chronic illnesses (Babazadeh, Dianatinasab et al. 2017). Relapses in MS with unknown course and severity are a big source of anxiety in patients and contribute to the development of fear in patients (Briones-Buixassa, Mila et al. 2015). The aim of the current study was to develop a measure that can quantify fear of relapse in patients suffering relapsing-remitting MS and to validate it in a separate sample of participants.

To test the validity of the fear of relapse scale RRMS patients were asked to complete two other measures assessing their intolerance of uncertainty (fear of unknown) and stress, anxiety and depression. Both scales and all subscales were significantly and positively correlated with individuals' total fear of relapse score. The Pearson correlation was at medium range suggesting a relationship between the fear of relapse scale, DASS, and IUS. Further investigations, however, showed that when two independent two-components factor analyses were run by pooling items of the fear of relapse scale once with the IUS and once with the DASS, items related to each scale were independently loaded on a separate component which suggest that in spite of a positive and significant correlation, each of the included measures assess independent constructs. This suggests that inclusion of the fear of relapse in research 
and clinical work with MS patients can capture characteristics in patients that cannot solely be explained by intolerance of uncertainty, of depression, anxiety and stress in patients.

To test the reliability, we examined the internal consistency, Cronbach's Alpha, and run the testretest. The Cronbach's alpha for the final format of the scale in the current study was 0.94 which is above the suggested threshold for the assessment of reliability (Tavakol, 2011). In line with this analysis, all items in the measure were positively and significantly correlated with the total score of the scale which indicates the high internal consistency of fear of relapse scale (Golafshani 2003). Furthermore, the test-retest reliability showed a high positive and significant correlations between each item's score in the test and that item's score in the retest. Above that, the total score test-retest reliability showed a high, positive correlation $(<0.7)$. Putting these results together it can be suggested that the fear of relapse scale is a reliable measure.

A principal component analysis of all 31 original items of the Fear of Relapse Scale resulted in the removal of 5 items and the remaining 26 items loaded on three factors. The first factor includes items that refer to the fear of and expectation of disability following the experience of a relapse. Disability is a concern for many patients who receive MS diagnosis. The link between the experience of a relapse and the progress of the disease causes patients to see each relapse as another step towards the disability and this can result in the experience of excessive fear of relapse in them. The second factor includes items that mention the fear of the psychological and physiological consequences of a relapse. Usually, relapses are followed by short-term (or in some cases an irreversible) losses in the function of the sensory and motor systems in the central nervous system. Uncertainty about the prognosis of the sensory and motor losses and about the future of patients' functions is another source of stress feeding their fear of relapse. The third factor includes items indicating limitations resulting from fear of a relapse. After the diagnosis, many patients become hypervigilant to the potential impact of the disease on their abilities and thus they may start to withdraw from many activities and stop accepting new challenges. This avoidance may contribute to the development of fear and further disability and lowering self-efficacy.

Fear of relapse in MS is a neglected variable when working on MS patients and in the studies investigating the psychological aspects of the diagnosis and living with MS. Psychological factors play a crucial role in the quality of life in patients with MS (Janssens, van Doorn et al. 2003). Better understanding of a chronic diseases requires a comprehensive approach to take 
different components into account specially when it comes to the quality of life as a multidimensional phenomenon (Fukuda, Straus et al. 1994). Understanding the source of fear in MS patients will assist professionals to grasp a more detailed image of the life of the patients to provide more effective interventions (Megari 2013). It is suggested that interventions for the improvement of the fear of relapse might be more effective if provided at the earlier stages of the development of the disease (Possa, Minacapelli et al. 2017).

This study has limitations as well. The sample of patients in the current study varied in the length of the onset of the disease. We did not find an association between the duration of the disease and fear of relapse scores, but previous studies suggested that the impact of psychological factors in the first year following the diagnosis is stronger on the quality of life of the patients (Possa, Minacapelli et al. 2017). Also, RRMS patients are very different in early symptoms that resulted in the diagnosis and in the clinical presentation of the disease (LangerGould, Popat et al. 2006). Future studies with larger number of the patients in their first year following the diagnosis may help us to characterize fear of relapse among them and to compare them to the patients with longer disease duration and more relapses experienced. Besides, the original version of the scale was developed in Persian. The English version provided in the supplementary has not gone through validation in English speaking population. Before using the measure for future studies in another language than Persian the measure should be validated in the target population by considering linguistic and cultural differences.

Taken together, this study presents a scale which promises a reliable and valid measure of fear of relapse in patients with RRMS. The Fear of Relapse Scale presented in this study showed good internal consistency and high test-retest reliability. This measure needs to be tested in the future studies to contribute to the understanding and improvement of the life of the patients suffering RRMS and may assist clinicians to identify the source of anxiety in patients and help them plan their interventions tailored to the clinical needs of the patient.

\section{Acknowledgments}

The authors would like to thank the Patient Support Unit of Actoverco Pharmaceuticals for helping with distributing the questionnaires to eligible patients

\section{Conflict of Interest Statement}

Authors declare no conflict of interest regarding the current submission. 


\section{References}

Akbari, F., M. Dehghani, A. Khatibi and T. Vervoort (2016). "Incorporating Family Function into Chronic Pain Disability: The Role of Catastrophizing." Pain Research \& Management.

Babazadeh, T., M. Dianatinasab, A. Daemi, H. A. Nikbakht, F. Moradi and S. Ghaffari-Fam (2017). "Association of Self-Care Behaviors and Quality of Life among Patients with Type 2 Diabetes Mellitus: Chaldoran County, Iran." Diabetes Metab J 41(6): 449-456.

Briones-Buixassa, L., R. Mila, M. f. A. J, E. Bufill, B. Olaya and F. X. Arrufat (2015). "Stress and multiple sclerosis: A systematic review considering potential moderating and mediating factors and methods of assessing stress." Health Psychol Open 2(2): 2055102915612271.

Buhr, K. and M. J. Dugas (2002). "The Intolerance of Uncertainty Scale: psychometric properties of the English version." Behav Res Ther 40(8): 931-945.

Burns, M. N., E. Nawacki, M. J. Kwasny, D. Pelletier and D. C. Mohr (2014). "Do positive or negative stressful events predict the development of new brain lesions in people with multiple sclerosis?" Psychol Med 44(2): 349-359.

Crombez, G., J. W. Vlaeyen, P. H. Heuts and R. Lysens (1999). "Pain-related fear is more disabling than pain itself: evidence on the role of pain-related fear in chronic back pain disability." Pain 80(1-2): 329-339.

Dehghani, M., S. Mohammadi, L. Sharpe and A. Khatibi (2018). "Attentional Bias to ThreatRelated Information Among Individuals With Dental Complaints: The Role of Pain Expectancy." Front Psychol 9: 786.

Duran, G., P. Herschbach, S. Waadt, F. Strian and A. Zettler (1995). "Assessing daily problems with diabetes: a subject-oriented approach to compliance." Psychol Rep 76(2): 515-521.

Freeston, M. H., J. Rhéaume, H. Letarte, M. J. Dugas and R. Ladouceur (1994). "Why do people worry?" Personality and Individual Differences 17(6): 791-801.

Fukuda, K., S. E. Straus, I. Hickie, M. C. Sharpe, J. G. Dobbins and A. Komaroff (1994). "The chronic fatigue syndrome: a comprehensive approach to its definition and study. International Chronic Fatigue Syndrome Study Group." Ann Intern Med 121(12): 953-959.

Golafshani, N. (2003). "Understanding Reliability and Validity in Qualitative Research." The Qualitative Report 8(4): 597-606.

Herschbach, P., P. Berg, A. Dankert, G. Duran, U. Engst-Hastreiter, S. Waadt, M. Keller, R. Ukat and G. Henrich (2005). "Fear of progression in chronic diseases: psychometric properties of the Fear of Progression Questionnaire." J Psychosom Res 58(6): 505-511.

Herschbach, P., G. Duran, S. Waadt, A. Zettler, C. Amm and B. Marten-Mittag (1997). "Psychometric properties of the Questionnaire on Stress in Patients with Diabetes--Revised (QSD-R)." Health Psychol 16(2): 171-174.

Holman, H. and K. Lorig (2004). "Patient self-management: a key to effectiveness and efficiency in care of chronic disease." Public Health Rep 119(3): 239-243.

Janssens, A. C., P. A. van Doorn, J. B. de Boer, F. G. van der Meche, J. Passchier and R. Q. Hintzen (2003). "Impact of recently diagnosed multiple sclerosis on quality of life, anxiety, depression and distress of patients and partners." Acta Neurol Scand 108(6): 389-395.

Khaje Mansoori, A., P. Mohammadkhani, M. Mazidi, M. Kami, M. Bakhshi Nodooshan and S. Shahidi (2016). "The Role of Metacognition and Intolerance of Uncertainty in Differentiating Illness Anxiety and Generalized Anxiety." Journal of Practice in Clinical Psychology 4(1): 57-65.

Langer-Gould, A., R. A. Popat, S. M. Huang, K. Cobb, P. Fontoura, M. K. Gould and L. M. Nelson (2006). "Clinical and demographic predictors of long-term disability in patients with relapsing-remitting multiple sclerosis: a systematic review." Arch Neurol 63(12): 1686-1691.

Lorig, K. R., D. S. Sobel, A. L. Stewart, B. W. Brown, Jr., A. Bandura, P. Ritter, V. M. Gonzalez, D. D. Laurent and H. R. Holman (1999). "Evidence suggesting that a chronic disease self- 
management program can improve health status while reducing hospitalization: a randomized trial." Med Care 37(1): 5-14.

Lovibond, P. F. and S. H. Lovibond (1995). "The structure of negative emotional states: comparison of the Depression Anxiety Stress Scales (DASS) with the Beck Depression and Anxiety Inventories." Behav Res Ther 33(3): 335-343.

Megari, K. (2013). "Quality of Life in Chronic Disease Patients." Health Psychol Res 1(3): e27.

Nielsen, J., J. Saliger, C. Montag, S. Markett, C. Nohring and H. Karbe (2018). "Facing the Unknown: Fear of Progression Could Be a Relevant Psychological Risk Factor for Depressive Mood States among Patients with Multiple Sclerosis." Psychother Psychosom 87(3): 190-192.

Norton, P. J. (2007). "Depression Anxiety and Stress Scales (DASS-21): psychometric analysis across four racial groups." Anxiety Stress Coping 20(3): 253-265.

Peterson, E. W., C. C. Cho and M. L. Finlayson (2007). "Fear of falling and associated activity curtailment among middle aged and older adults with multiple sclerosis." Mult Scler 13(9): 11681175.

Possa, M. F., E. Minacapelli, S. Canale, G. Comi, V. Martinelli and M. Falautano (2017). "The first year after diagnosis: psychological impact on people with multiple sclerosis." Psychol Health Med 22(9): 1063-1071.

Strober, L. B. (2018). "Quality of life and psychological well-being in the early stages of multiple sclerosis (MS): Importance of adopting a biopsychosocial model." Disabil Health J 11(4): 555561.

Wells, K. B., J. M. Golding and M. A. Burnam (1988). "Psychiatric disorder in a sample of the general population with and without chronic medical conditions." Am J Psychiatry 145(8): 976981. 


\begin{tabular}{|c|c|c|c|c|c|c|}
\hline \multicolumn{7}{|c|}{$\begin{array}{l}\text { Table Supplementary 1. English Version of The Fear of Relapse Scale } \\
\text { Statements below depict the thoughts that one may think regarding their medical condition. Please } \\
\text { consider each item carefully and then mark the number which corresponds with your level of agreement } \\
\text { best. }\end{array}$} \\
\hline Number & Statements & Never & Rarely & Sometimes & $\begin{array}{l}\text { Most of } \\
\text { the time }\end{array}$ & Always \\
\hline 1 & $\begin{array}{l}\text { I feel another relapse is about to } \\
\text { happen whenever I get red eyes or feel } \\
\text { pain behind my eyes. }\end{array}$ & & & & & \\
\hline 2 & $\begin{array}{l}\text { Another relapse means another } \\
\text { hospitalization }\end{array}$ & & & & & \\
\hline 3 & $\begin{array}{l}\text { My appearance gives away the fact that } \\
\text { I am experiencing a relapse. }\end{array}$ & & & & & \\
\hline \begin{tabular}{|l}
4 \\
\end{tabular} & $\begin{array}{l}\text { Each relapse means the disease is } \\
\text { spreading in the nervous system. }\end{array}$ & & & & & \\
\hline 5 & $\begin{array}{l}\text { I do a lot of exercise because I am afraid } \\
\text { of experiencing a relapse. }\end{array}$ & & & & & \\
\hline 6 & I don't drive in fear of a relapse. & & & & & \\
\hline 7 & $\begin{array}{l}\text { Whenever a relapse happens, it can } \\
\text { only be managed with more } \\
\text { corticosteroids. }\end{array}$ & & & & & \\
\hline 8 & $\begin{array}{l}\text { The disease will comeback in a relapse } \\
\text { if I stop taking medication for one } \\
\text { month. }\end{array}$ & & & & & \\
\hline 9 & $\begin{array}{l}\text { Each relapse takes me one step closer } \\
\text { to becoming bedridden. }\end{array}$ & & & & & \\
\hline 10 & $\begin{array}{l}\text { Each relapse will make me more } \\
\text { dependent on other people. }\end{array}$ & & & & & \\
\hline 11 & $\begin{array}{l}\text { Thinking about relapses makes my } \\
\text { heart jitter. }\end{array}$ & & & & & \\
\hline 12 & $\begin{array}{l}\text { After each relapse, I put all my task and } \\
\text { duties aside. }\end{array}$ & & & & & \\
\hline 13 & $\begin{array}{l}\text { A severe relapse with strong symptoms } \\
\text { can result in death. }\end{array}$ & & & & & \\
\hline 14 & $\begin{array}{l}\text { Any experience of numbness and } \\
\text { tingling in my limbs means I am having } \\
\text { another relapse. }\end{array}$ & & & & & \\
\hline 15 & Heat can trigger a relapse. & & & & & \\
\hline 16 & Relapses cause memory decline. & & & & & \\
\hline 17 & $\begin{array}{l}\text { Relapses cause loss of control over } \\
\text { movement and posture stability. }\end{array}$ & & & & & \\
\hline \begin{tabular}{|l}
18 \\
\end{tabular} & $\begin{array}{l}\text { When I think about relapse, I am unable } \\
\text { to think about anything else. }\end{array}$ & & & & & \\
\hline 19 & Grave news can trigger a relapse. & & & & & \\
\hline 20 & $\begin{array}{l}\text { Due to fear of a sudden relapse, I try } \\
\text { not to take a shower when I am home } \\
\text { alone. }\end{array}$ & & & & & \\
\hline 21 & $\begin{array}{l}\text { Relapses worsen the level of fatigue I } \\
\text { feel. }\end{array}$ & & & & & \\
\hline
\end{tabular}




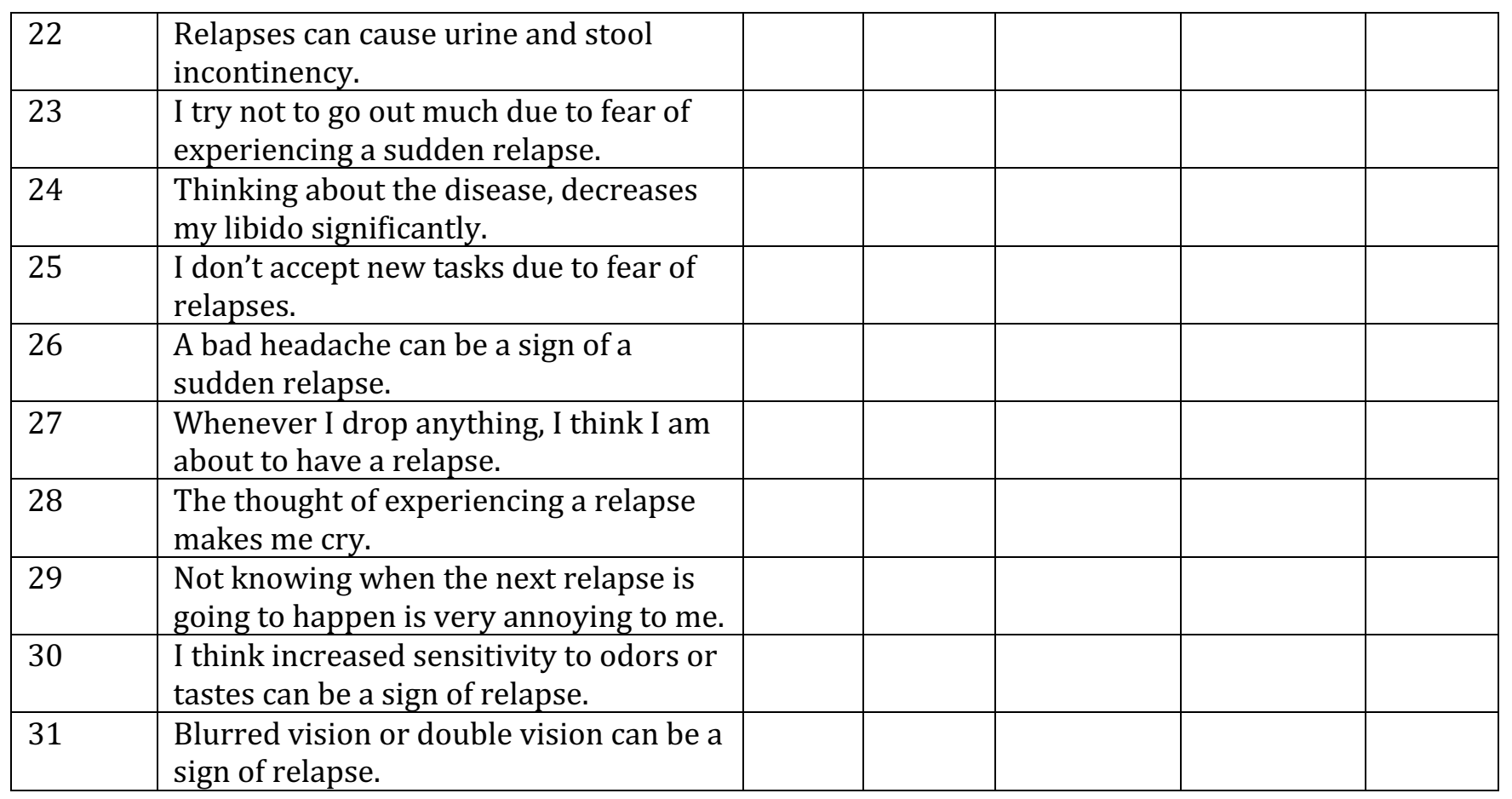

